\title{
SELF-DECOMPOSITION OF HYDROGEN PEROXIDE ON THE SURFACE OF DISPERSE CARBON BLACK
}

\author{
Galina I. Razdyakonova, Vladimir A. Likholobov \\ Institute of Hydrocarbons Processing, Russian Academy of Sciences, Siberian Branch, http://www.ihcp.ru \\ 644040 Omsk, Russian Federation \\ grazdyakonova@mail.ru,val@ihcp.ru
}

Olga A. Kokhanovskaya

Omsk State Technical University, http://www.omgtu.ru

644050 Omsk, Russian Federation

kokhanovskaya@omgtu.ru

\begin{abstract}
The study aimed to compare the catalytic activities of different carbon black grades in the decomposition of hydrogen peroxide and to reveal the properties of carbon black surface affecting the kinetic parameters of the reaction. The catalytic activities of different carbon black grades, both the channel KK354 and the furnace N121, N326, P161, P267-E and P366-E, were compared in the decomposition of hydrogen peroxide to reveal the most essential properties of carbon black surface affecting a kinetic parameter of the reaction - its activation energy. The knowledge of activation energies for the decomposition of hydrogen peroxide by different carbon black grades will allow choosing the most efficient set of available grades for their joint oxidation and optimization of the functional composition of the product and other process variables. The study has shown that a direct relationship between catalytic activity and specific surface area of carbon black is absent. The disturbing factor is the surface roughness. The functionalization mechanism of the carbon black surface upon its oxidation by hydrogen peroxide with co-agents, ozone and singlet oxygen, was considered. The highest oxidation state of carbon black is reached by increasing the content of carboxyl and lactone groups with the use of hydrogen peroxide in a concentration of $30 \%$ in the liquid-phase process and air enriched with singlet oxygen.
\end{abstract}

Keywords: carbon black, oxidation, hydrogen peroxide, ozone, singlet oxygen, functional composition, activation energy.

PACS: 81.05Uw, 81.65 Mq

Bibliography - 30 references

Received 04.09.2015

RENSIT, 2015, 7(2):180-190

DOI: $10.17725 /$ rensit.2015.07.180

CONTENTS

1. INTRODUCTION (180)

2. Materials and Methods (181)

3. Results (182)

4. Discussion (187)

5. Conclusion (188)

Acknowledgments (188)

REFERENCES (188)

\section{INTRODUCTION}

After the discovery of the hydrogen peroxide molecule $\left(\mathrm{H}_{2} \mathrm{O}_{2}\right)$ by a French chemist Louis Jacques Thénard in 1818, many studies were devoted to the reactions involving this substance, a review of such studies being made in monographs $[1,2]$.

Hydrogen peroxide enters the oxidation and reduction reactions, produces clathrates, and decomposes to yield oxygen and water. As an oxidant, hydrogen peroxide enters the reactions by the electron transfer, ionic or free radical mechanism. The mechanism of its decomposition is quite complicated, comprises several reactions and depends on the presence of other substances in the reaction system.

Hydrogen peroxide is currently an important type of chemical products and is widely used as 
a catalyst, hydrogenation and epoxidation agent, foaming agent in the production of porous materials, in functionalization of aromatic compounds, as a bleacher and antiseptic, a reagent in the production of solid sources of active oxygen such as sodium percarbonate, zinc and calcium peroxide, urea peroxohydrate, and others $[3,4]$.

Hydrogen peroxide is a bulky chemical; its annual output in Russia reaches ca. 100000 tons. It is produced by the technology of liquidphase oxidation of isopropyl alcohol (the Shell process), by the anthraquinone technology consisting in the reduction of anthraquinone to anthraquinol and its subsequent oxidation to anthraquinol with the formation of $\mathrm{H}_{2} \mathrm{O}_{2}$ as a by-product (the BASF or Solvay processes), and by the catalytic synthesis from elements.

Hydrogen peroxide as an oxidant is active over the entire $p H$ range: its oxidation potential $\varphi^{\circ}$ varies from $1.736 \mathrm{~V}$ at $p H$ near 0 to $0.878 \mathrm{~V}$ at $p H 14$. Thus, when the peroxide transforms into hydrogen oxide in an acid medium, the system has the strong oxidizing nature [5]: $\mathrm{H}_{2} \mathrm{O}_{2}+2 \mathrm{H}^{+} \leftrightarrow 2 \mathrm{H}_{2} \mathrm{O}\left(\varphi_{0}=+1.77 \mathrm{~V}\right)$, in a basic medium, the process occurs by the consecutive scheme of ionic transformations from perhydroxyl ion to hydroxyl [6]:

$\mathrm{H}_{2} \mathrm{O}_{2}+\mathrm{OH} \leftrightarrow \mathrm{HO}_{2}^{-}+\mathrm{H}_{2} \mathrm{O} \leftrightarrow 3 \mathrm{OH}\left(\varphi^{\circ}=+0.88 \mathrm{~V}\right)$ $\mathrm{HO}_{2}^{-}+\mathrm{OH} \leftrightarrow \mathrm{O}_{2}^{-}+\mathrm{H}_{2} \mathrm{O} \leftrightarrow 4 \mathrm{OH}\left(\varphi^{\circ}=+0.40 \mathrm{~V}\right)$, or with a release of oxygen:

$$
\mathrm{H}_{2} \mathrm{O}_{2} \rightarrow \mathrm{O}_{2}+2 \mathrm{H}^{+}+2 \mathrm{e}^{-}\left(\varphi^{\circ}=+0.68 \mathrm{~V}\right) \text {. }
$$

In any variant of the reaction, its byproducts do not cause any contamination, and the liquid form of hydrogen peroxide is convenient for use. One of its applications is the oxidation of carbon black [7-9].

Carbon black is employed as a filler for polymers and anode pastes, and also as a pigment, adsorbent and catalyst. Its synthesis proceeds at a temperature above $1000^{\circ} \mathrm{C}$, which excludes its surface functionalization [10]. The most promising oxidants of carbon black at low temperatures are active oxygen species: hydrogen peroxide, ozone, and singlet oxygen [11-14].

Investigation of self-decomposition of hydrogen peroxide on the surface of disperse carbon is of interest not only for obtaining carbon black species but also for studying the interactions of $s p^{2}$ carbon with the strained hydrogen peroxide molecule whose decomposition on the carbon surface can give both the triplet oxygen species and the chemically active singlet oxygen species.

In this connection, it seems interesting to compare the chemical activities not only of hydrogen peroxide but also of singlet oxygen, ozone and other active oxygen species simultaneously interacting with the carbon surface (graphene layers).

The goal of the study was to compare the catalytic activities of different carbon black grades in the decomposition of hydrogen peroxide and to elucidate the carbon surface properties that can exert an effect on the kinetic parameters of the reaction.

\section{MATERIALS AND METHODS}

The study was performed with the channel carbon black $K 354$ (Khazar Chemical Plant, the Republic of Turkmenistan) and the furnace carbon black N121, N326 (Omsktekhuglerod PLC company), P161, P267-E and P366-E (Institute of Hydrocarbons Processing SB RAS, Department of Experimental Processes), and an aqueous solution of medical grade hydrogen peroxide, specs GOST 177-88.

The hydrogen peroxide decomposition experiments were carried out in a volumetric setup. A carbon black sample and $17.5 \mathrm{~cm}^{3}$ of a $0.6 \mathrm{M}(2 \%)$ aqueous solution of hydrogen peroxide, whose $p H$ value was adjusted by adding an aqueous solution of ammonia, were placed in a flask that was mounted in a thermostat and connected to a burette for gas collection. The volume of oxygen released at 
different time intervals was reduced to normal conditions.

Upon termination of the experiment, carbon black was separated from the suspension by microfiltration and washed with distilled water; after that, $p H$ of its aqueous suspension was measured according to GOST 25699-6.-90 on a pH-150MI instrument (Izmeritelnaya Tekhnika PLC company), and the functional composition was determined by selective neutralization $[15,16]$ and differential potentiometry [17].

The interaction of carbon black with hydrogen peroxide and activators (singlet oxygen or ozone) was carried out in a rotating flask under stirring of carbon black grains with a $2 \%$ aqueous solution of hydrogen peroxide in a weight ratio 1:1 in the air that passed through an ozonizer or a generator of singlet oxygen at a temperature of $25 \pm 2^{\circ} \mathrm{C}$ for $5 \mathrm{~min}$.

Ozone was generated in an OZONER ozonizer (Formula Zdorovya) with an ozone output of $400 \mathrm{mg} / \mathrm{h}$.

Singlet oxygen was generated in an AIRNERGY + Basis Plus device (Airnergy AG, Germany) with photocatalytic activation $(\lambda=$ $634 \mathrm{~nm}$ ) and a flow rate of $4 \mathrm{~L} / \mathrm{h}$.

The specific surface area (full NSA and external $S T S A$ ) was measured by the lowtemperature nitrogen adsorption isotherm on a Gemini 2380 (Micromeritics) analyzer using a technique reported in [18].

The Raman spectra were recorded on a DXR Smart Raman (ThermoScientific) dispersive spectrometer at a laser excitation wavelength of $633 \mathrm{~nm}$ and laser power of $5 \mathrm{~mW}$. The spectra were accumulated from 15 scans at accumulation time of $60 \mathrm{~s}$. The degree of order of the particles was characterized by the intensity ratio of absorption bands $I D / I G$ similar to [19].

The IR spectra were recorded on an IR Prestige-21 (Shimadzu) spectrometer with a resolution $4 \mathrm{~cm}^{-1}$ and accumulation from 50 scans, and then processed using the ORIGIN software package (baseline correction and smoothing). Preparation of a sample included sedimentation of small particles on a $\mathrm{BaF}_{2}$ plate to obtain a specified homogeneous thickness of the layer.

Nanostructure of carbon black was observed on the images obtained by high resolution transmission electron microscopy (HRTEM) using a JEM 2100 (JEOL) electron microscope with an accelerating voltage of 200 $k V$ and a line-in-line resolution of $0.14 \mathrm{~nm}$.

The XRD study of carbon black samples was carried out on a D8 Advance (Bruker) powder diffractometer using $C u_{K \alpha}$ radiation. The samples were scanned in an angular range of $10-70^{\circ}(2 \Theta)$ with a scanning step $0.02^{\circ}$ and accumulation time $1 s$. The interplanar spacing and crystallite size along (002) plane were calculated by the Selyakov-Scherrer equation $d_{002}=\lambda /\left(2 \sin \left(\Theta_{\mathrm{i}}\right)\right)$, $L_{i}=\mathbf{k} \cdot \lambda /\left(B_{i} \cdot \cos \left(\Theta_{i}\right)\right)$,

where $i=(002)-(100)$, respectively, $L_{c}$ and $L_{a}$; $\lambda$ is the wavelength of $C u_{\mathrm{K} \alpha}$ radiation equal to $0.154 \mathrm{~nm} ; \Theta_{i}^{\circ}$ is the position of reflection; $\mathbf{k}$ is the coefficient determined by the particle size: $\mathbf{k}=0.89$ for the (002) peak and 1.84 for the (100) peak; and $B_{i}$ is the full width at halfmaximum of the $i$ peak (FWHM), rad.

The Fityk program was employed for data processing and deconvolution of the peaks.

The oxygen content was measured on a Elementar Vario Cube analyzer of $C, H, N, S, O$, $\mathrm{Cl}$ by thermal destruction at $1100^{\circ} \mathrm{C}$.

\section{RESULTS}

Fig. 1 shows the HRTEM images of carbon black.

One can see in Fig. 1 that the main morphological form of the carbon black samples is represented by the globules whose structure includes the ordered crystal regions consisting of 3-4 graphene layers. 


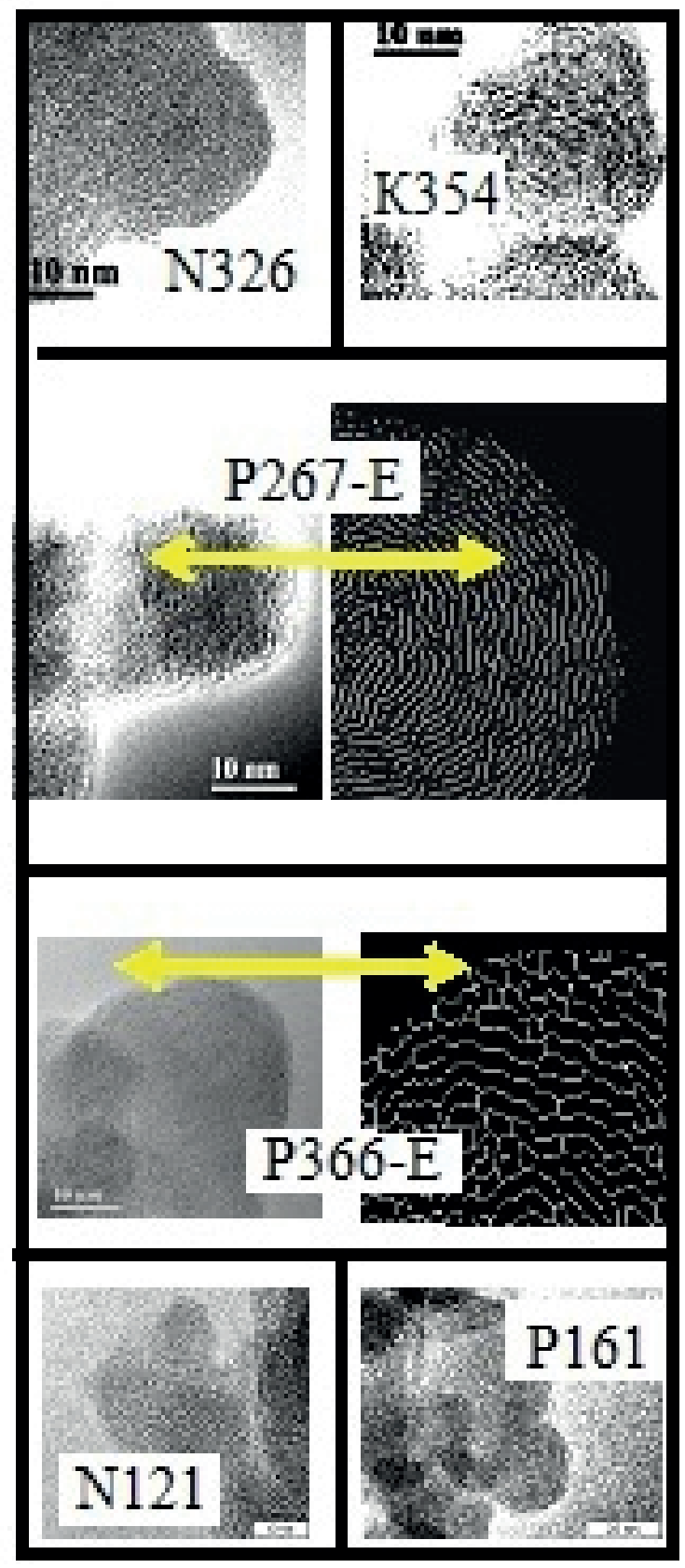

Fig. 1. TEM image of the particles of carbon black samples.

The high-contrast images show that the graphene layers at the periphery of the particles are curved toward their center because the particles are strained by the valence bonds with the edge atoms.

Table 1 lists the values of interplanar spacing $d_{002}$, length of graphene layers $L_{a}$, fraction of end carbon atoms $D$ calculated from the data of [20] by the formula $D=29.602 \cdot L_{a}^{-0.809}$, graphitization degree $\gamma$ of the samples calculated by the formula
Table 1

Main characteristics of the initial carbon black substructure

\begin{tabular}{|l|c|c|l|c|c|c|c|c|}
\hline $\begin{array}{c}\text { Sample } \\
\text { grade }\end{array}$ & $\begin{array}{l}\mathrm{NSA}, \\
\mathrm{m}^{2} / \mathrm{g}\end{array}$ & $\mathrm{K}_{\mathrm{r}}$ & $\begin{array}{l}d_{\mathrm{oO2}^{\prime}} \\
\mathrm{nm}\end{array}$ & $\begin{array}{l}L_{c^{\prime}} \\
\mathrm{nm}\end{array}$ & $\begin{array}{l}L_{\mathrm{a}^{\prime}} \\
\mathrm{nm}\end{array}$ & $\begin{array}{c}\text { Fraction } \\
(\mathrm{D}) \text { of } \\
\text { edge } \\
\text { atoms, } \\
\%\end{array}$ & $\begin{array}{c}\text { Gra- } \\
\text { phiti- } \\
\text { zation } \\
\text { degree } \\
\mathrm{Y}\end{array}$ & $\begin{array}{c}\text { Degree } \\
\text { of } \\
\text { order, } \\
I_{D} I_{G}\end{array}$ \\
\hline P161 & 216 & 1.3 & 0.367 & 1.6 & 4.5 & 9 & 0.16 & \\
\hline $\mathrm{N} 121$ & 117 & 1.1 & 0.373 & 1.4 & 3.8 & 10 & - & 1.4 \\
\hline P267-E & 255 & 1.6 & 0.368 & 1.7 & 4.2 & 9 & 0.13 & \\
\hline P366-E & 311 & 1.5 & 0.359 & 1.76 & 3.3 & 11 & 0.37 & 1.4 \\
\hline N326 & 77 & 1.0 & 0.358 & 1.64 & 3.0 & 12 & 0.40 & 1.4 \\
\hline K354 & 102 & 1.2 & 0.356 & 1.97 & 3.0 & 12 & 0.45 & 1.3 \\
\hline
\end{tabular}

$\gamma=\left(0.373-d_{002}\right) /(0.373-0.335)$

and stack thickness $L$ of the tested samples.

According to Table 1, the lowest structural organization is observed for the particles of carbon black N121, P267-E and P161, and the highest for N326, P366-E and K354.

The samples being compared differ in their specific surface areas and roughness coefficients related to the pore length shorter than $2 \mathrm{~nm}$ [11]. The surface roughness coefficient was calculated by the formula

$$
K_{\mathrm{r}}=N S A / S T S A \text {. }
$$

The catalytic properties of carbon black in the decomposition of hydrogen peroxide were characterized by the activation energy $\mathrm{E}_{a}$ of $\mathrm{H}_{2} \mathrm{O}_{2}$ decomposition at $p H$ of a hydrogen peroxide solution equal to 4.4 and 9.2.

It is supposed that at $p H$ above 8.7 the decomposition of hydrogen peroxide switches from homogeneous to heterogeneous mechanism [2]. In a strongly basic region of the $p H$ scale, the authors of [21] revealed an "energy well" for the process of hydrogen peroxide decomposition in a $p H$ range of 10.5-11.5.

In this connection, it should be noted that the carbon black surface is inhomogeneous with respect to isoelectric $p H$ : it has iso- $p H$ of 1 to 4 in a strong acid medium, above 11 in a strong basic medium, and 3 to 10 in the middle range [22]. So, the presence of carbon black may lead to different rates of hydrogen peroxide selfdecomposition depending on the location of $\mathrm{H}_{2} \mathrm{O}_{2}$ molecules adsorbed on the carbon surface, and to different mechanisms of the process. 
Table 2

Experimental values of activation energy $E_{\text {a }}$ for decomposition of $\mathrm{H}_{2} \mathrm{O}_{2}$ at different $\mathrm{pH}$ of the medium and weights of carbon black in the reaction vessel

\begin{tabular}{|c|c|c|c|c|}
\hline \multirow{3}{*}{$\begin{array}{l}\text { Carbon } \\
\text { black } \\
\text { grade }\end{array}$} & \multicolumn{4}{|c|}{$\begin{array}{c}E_{a} \text { of the reaction upon introduction of carbon black } \\
\text { sample of mass } m(g) \text { into reaction vessel }\end{array}$} \\
\hline & 0.2642 & 0.3775 & 0.5285 & 0.7549 \\
\hline & \multicolumn{4}{|c|}{$\mathrm{pH}$ of hydrogen peroxide solution equal to 4.4} \\
\hline N326 & 68.3 & 62.3 & 58.8 & 56.6 \\
\hline N121 & 57.5 & 55.1 & 50.7 & 47.8 \\
\hline $\mathrm{P} 161$ & 55.5 & 50.8 & 48.5 & 44.5 \\
\hline P366-E & 52.0 & 48.3 & 49.2 & 43.4 \\
\hline P267-E & 35.0 & 39.5 & 27.5 & 33.0 \\
\hline \multirow[t]{2}{*}{ К354 } & 39.8 & 41.5 & 37.0 & 37.6 \\
\hline & \multicolumn{4}{|c|}{$p H$ of hydrogen peroxide solution equal to 9.2} \\
\hline N326 & 57.8 & 56.9 & 49.8 & 46.2 \\
\hline N121 & 47.4 & 41.2 & 33.9 & 30.1 \\
\hline P161 & 41.1 & 39.1 & 33.7 & 28.6 \\
\hline P366-E & 32.4 & 31.5 & 26.7 & 21.5 \\
\hline P267-E & 34.5 & 36.6 & 29.6 & 22.3 \\
\hline К354 & 38.8 & 41.4 & 33.8 & 36.5 \\
\hline
\end{tabular}

The activation energy of the reaction was calculated by a graphical method using the Arrhenius equation. The reaction order was equal to 1 , which does not contradict the data reported in [23]. In a blank run (without carbon black) performed in a basic medium, $\mathrm{E}_{a}$ of $\mathrm{H}_{2} \mathrm{O}_{2}$ decomposition was $73 \mathrm{~kJ} / \mathrm{mol}$, and in an acid medium, $87.3 \mathrm{~kJ} / \mathrm{mol}$. According to the literature, the least activation energies of hydrogen peroxide decomposition are observed at $p H$ from 10.5 to 11.5 and are attributed to ionic transformations of hydrogen peroxide molecules [6]. At $p H$ above 12, the radical ion

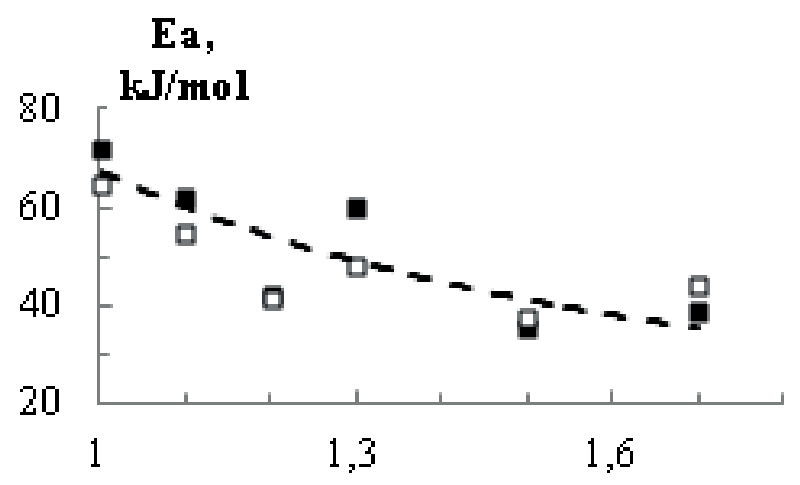

NSA/STSA

Fig. 2. Activation energies of hydrogen peroxide decomposition at pH 4.4 (dark markers) and 9.2 (bright markers) in the presence of carbon black with different roughness coefficients $K_{\dot{r}}$.
$\mathrm{pH}$

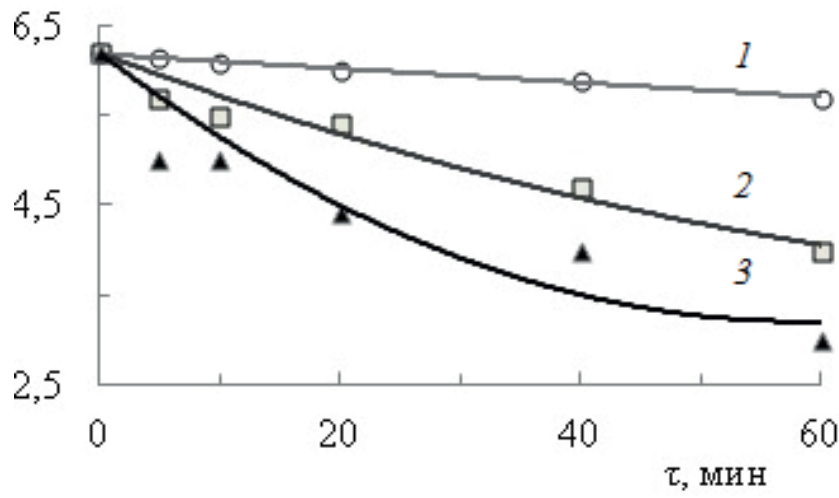

Fig. 3. Changes in $p H$ of an aqueous suspension of carbon black N121 under the action of bydrogen peroxide (1), ozone

(2) and a mixture of bydrogen peroxide and ozone (3). species are formed [24], thus making changes in the activation energy insignificant.

It is expected that on the main parts of carbon black surface (basal planes and regions occupied by neutral functional groups like quinone, anhydride, carbonyl, aldehyde and pyrone ones) the decomposition of $\mathrm{H}_{2} \mathrm{O}_{2}$ with a release of oxygen will be more pronounced than in the regions with acid (carboxyl) functional groups.

In the presence of carbon black samples of different weight in the reaction vessel, a decrease in the activation energy of hydrogen peroxide self-decomposition caused by the catalytic action of the carbon surface was observed (Table 2).

In terms of $1 \mathrm{~g}$ carbon black (5.4\% in the reaction mixture), $E_{a}$ of the reaction at different $p H$ values of the reaction mixtures varied from 50 to $20 \mathrm{~kJ} / \mathrm{mol}$ (Fig. 2).

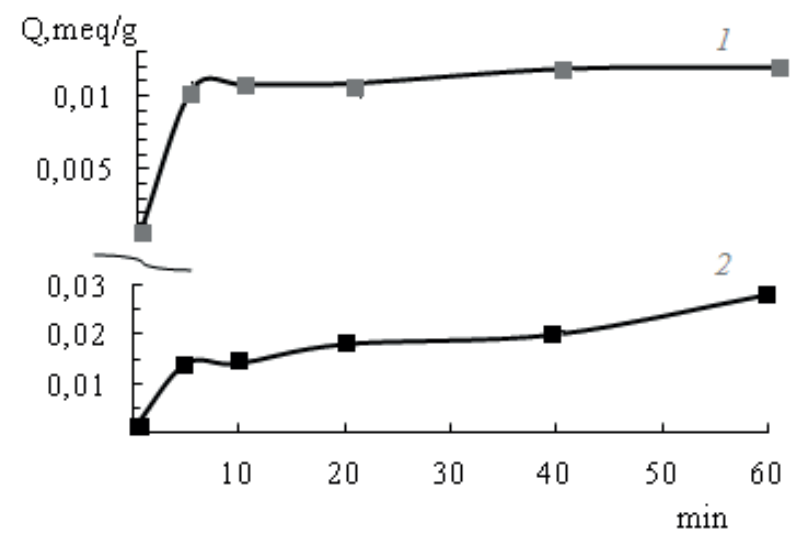

Fig. 4. Changes in the content of carboxyl groups upon interaction of carbon black N121 with ozone (1) and a mixture of bydrogen peroxide and ozone (2). 


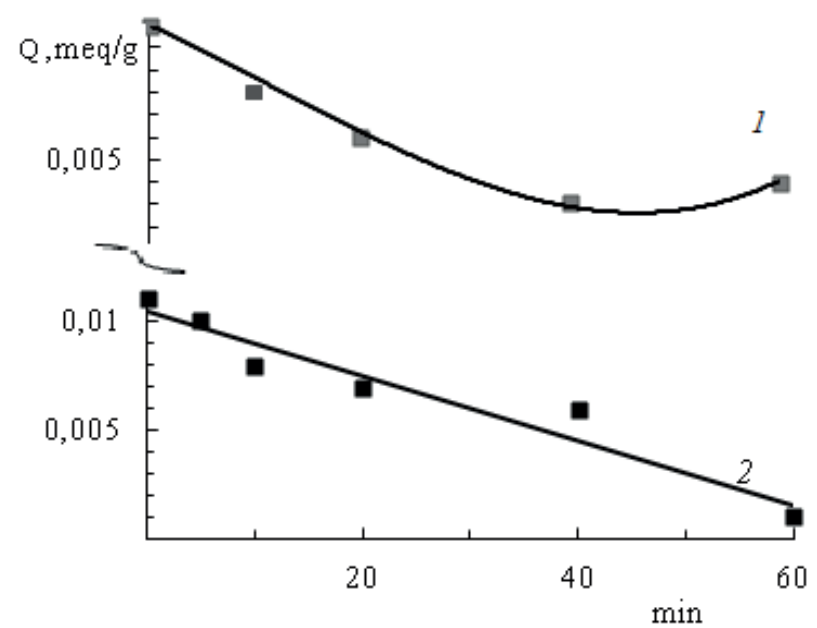

Fig. 5. Changes in the content of phenol groups upon interaction of carbon black N121 with ozone (1) and a mixture of bydrogen peroxide and ozone (2).

As shown in Fig. 2, $E_{a}$ of the hydrogen peroxide decomposition varies with the carbon black sample. The catalytic activity of carbon black increases with raising the $K_{r}$ value. The effect of $K_{r}$ on a decrease in $E_{a}$ value is most pronounced in an acid medium. This is caused by the formation of phenol groups during the oxidation of carbon black, which accelerate the reaction. The carboxyl groups shift $p H$ of the aqueous suspension of carbon black to the acid region, thus inhibiting the decomposition of hydrogen peroxide.

Indeed, when carbon black is oxidized by hydrogen peroxide in an acid medium with

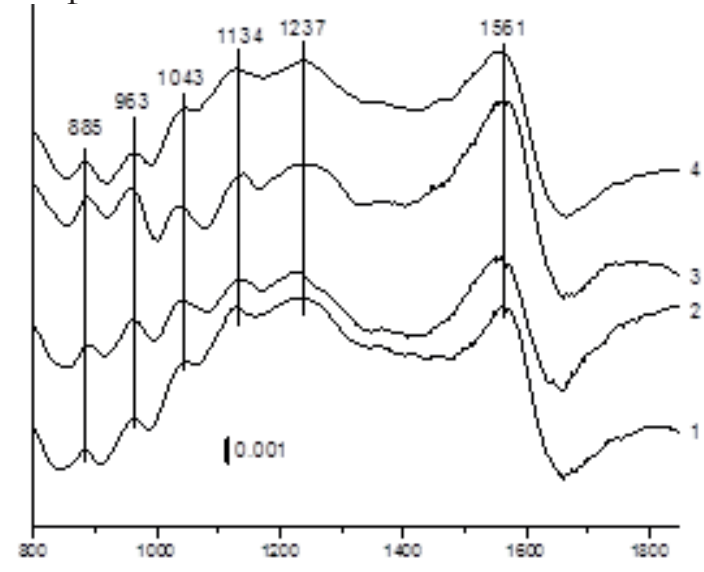

$a$

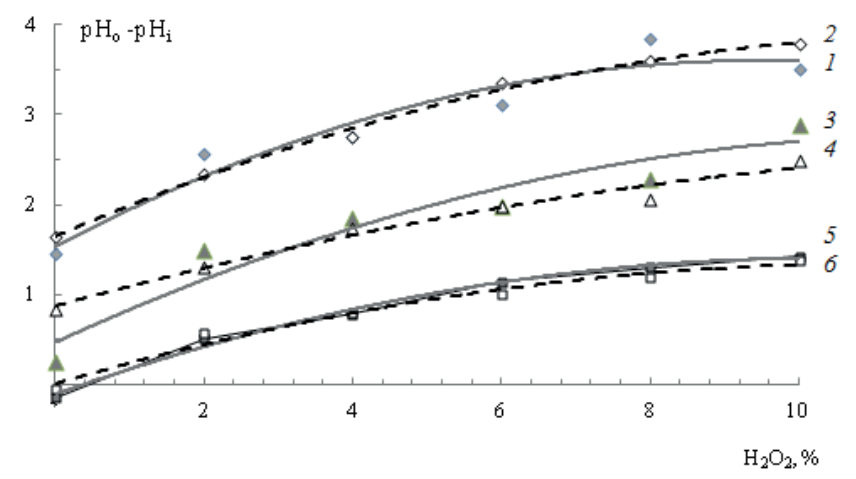

Fig. 6. $p H$ of an aqueous suspension of carbon black N326 (1, 2), P366-E (3, 4) and N121 (5, 6) versus the concentration of bydrogen peroxide in the presence of ozone $(1,3,5)$ or singlet oxygen $(2,4,6)$.

ozone as the co-agent, a much faster decrease in $p H$ of the aqueous suspension is observed (Fig. 3), which is caused by the generation of carboxyl groups (Fig. 4) due to a decreasing content of phenol groups (Fig. 5).

It seems that singlet oxygen does not activate hydrogen peroxide, in distinction to ozone; singlet oxygen is an additional reagent, but its curve of the carbon black $\mathrm{pH}$ is similar to the ozone activation curve (Fig. 6).

The IR spectra of the initial samples N121, P366-E and N326 (Fig. 7) show the absorption bands (a.b.) in the region of $1200-1300 \mathrm{~cm}^{-1}$ that are attributed to stretching vibrations of the $C-O$ bonds in ethers and lactones.

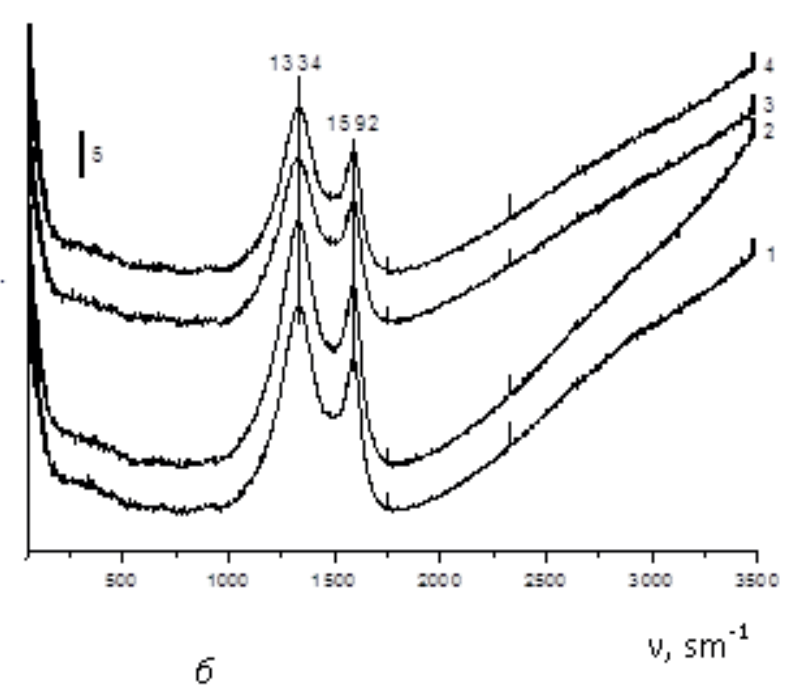

Fig. 7. The IR (a) and Raman (b) spectra of carbon black N121: 1 - initial, 2 - oxidized by 30\% bydrogen peroxide, 3 - by $2 \%$ bydrogen peroxide with ozone; 4 - by $2 \%$ bydrogen peroxide with singlet oxygen. 
The bands corresponding to stretching vibrations of the $\mathrm{C}-\mathrm{O}$ bonds in alcohols and phenols are observed in the spectral region of 1000-1200 $\mathrm{cm}^{-1}$. The IR spectrum of the tested sample has an additional band at 1550-1600 $\mathrm{cm}^{-1}$, which corresponds to stretching vibrations of the $C=C$ bonds in aromatic structures.

After the oxidative treatment, neither the disappearance of existing a.b. nor the appearance of new bands was observed in $I R$ spectra of the tested samples.

In the Raman spectra at $\lambda_{0} 633 \mathrm{~nm}$, the intensity ratio of $D$ band to $G$ band of 1.3-1.4 for the initial carbon materials N121, P367-E, N326 and K354 testifies to an amorphous structure of the samples under consideration. According to the Raman data, the intensity ratio of $D$ band to $G$ band did not change after the oxidative treatment.

However, the oxidation process was accompanied by an increase in the oxygen content in carbon black and by changes in its substructure, as shown by XRD (Fig. 8).

Thus, the oxidative treatment of carbon black results in a partial destruction of the graphene layers and changes in the particle substructure.

The efficiency of the oxidizing systems was estimated from the oxidation degree of functional groups for $5 \mathrm{~min}$ at a temperature of $25^{\circ} \mathrm{C}$ (Table 3), i.e. from the ratio of the sum of carboxyl and lactone groups (which are the end groups in the oxidation cycle) to the initial phenol groups.

As follows from Table 3, the efficiency of action of the oxidizing systems on carbon black decreases in the following order:

P366-E: 30\% $\mathrm{H}_{2} \mathrm{O}_{2}>{ }^{1} \mathrm{O}_{2}>\left(2 \% \mathrm{H}_{2} \mathrm{O}_{2}+{ }^{1} \mathrm{O}_{2}\right)$ $>\mathrm{O}_{3},\left(\mathrm{H}_{2} \mathrm{O}_{2} 2 \%+\mathrm{O}_{3}\right)$,

N121: ${ }^{1} \mathrm{O}_{2}>30 \% \mathrm{H}_{2} \mathrm{O}_{2}>\left(2 \% \mathrm{H}_{2} \mathrm{O}_{2}+{ }^{1} \mathrm{O}_{2}\right)>$ $\mathrm{O}_{3},\left(\mathrm{H}_{2} \mathrm{O}_{2} 2 \%+\mathrm{O}_{3}\right)$,

N326: $30 \% \mathrm{H}_{2} \mathrm{O}_{2}>{ }^{1} \mathrm{O}_{2}>\mathrm{O}_{3}>\left(2 \% \mathrm{H}_{2} \mathrm{O}_{2}+\right.$ $\left.{ }^{1} \mathrm{O}_{2}\right)>\left(\mathrm{H}_{2} \mathrm{O}_{2} 2 \%+\mathrm{O}_{3}\right)$.

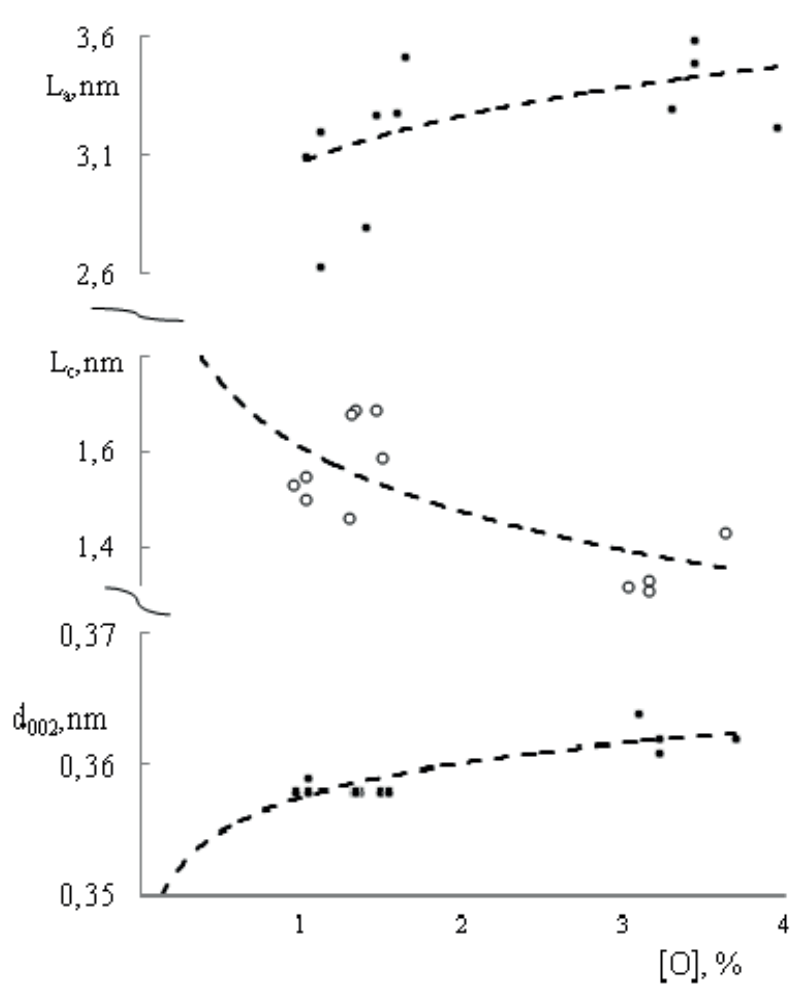

Fig. 8. La, Lc and $d_{002}$ parameters of carbon black N326, N121 and P366-E versus oxygen content.

The highest oxidation level of carbon black is reached due to increasing the number of carboxyl and lactone groups with the use of hydrogen peroxide in a concentration of $30 \%$ in the liquid-phase process and air enriched

Content of acid functional groups on the surface of initial and oxidized carbon black

\begin{tabular}{|l|c|c|c|c|c|c|}
\hline \multirow{2}{*}{ Groups } & \multirow{2}{*}{$\begin{array}{c}\text { Ini- } \\
\text { tial }\end{array}$} & \multicolumn{6}{|c|}{$\begin{array}{c}\text { Content of groups in carbon black, } \\
\text { mg-eq/g, after exposure to oxidants }\end{array}$} \\
\cline { 3 - 7 } & & $\mathrm{O}_{3}$ & $\begin{array}{c}\mathrm{H}_{2} \mathrm{O}_{2} \\
30 \%\end{array}$ & $\begin{array}{c}\mathrm{H}_{2} \mathrm{O}_{2} \\
2 \%+\mathrm{O}_{3}\end{array}$ & $\begin{array}{c}\mathrm{H}_{2} \mathrm{O}_{2} \\
2 \%+{ }^{2} \mathrm{O}_{2}\end{array}$ & ${ }^{1} \mathrm{O}_{2}$ \\
\hline Phenol & 0.037 & 0.001 & 0.020 & 0.017 & 0.014 & 0.014 \\
\hline Carboxyl & 0.003 & 0.01 & 0.035 & 0.012 & 0.013 & 0.006 \\
\hline Lactone & 0.006 & 0.013 & 0.042 & 0.003 & 0.006 & 0.028 \\
\hline Oxidation level & 0.2 & 2 & 3.8 & 0.8 & 1.3 & 2.4 \\
\hline & 0.010 & 0.064 & 0.039 & 0.031 & 0.010 & 0.008 \\
\hline Phenol & 0.002 & 0.003 & 0.021 & 0.008 & 0.002 & 0.003 \\
\hline Carboxyl & 0.018 & 0.031 & 0.053 & 0.041 & 0.018 & 0.034 \\
\hline Lactone & 2 & 0.5 & 1.8 & 1.5 & 2 & 4.6 \\
\hline Oxidation level & \multicolumn{7}{|c|}{$\mathrm{N} 121$} \\
\hline & 0.025 & 0.025 & 0.006 & 0.025 & 0.014 & 0.028 \\
\hline Phenol & 0.027 & 0.017 & 0.051 & 0.021 & 0.028 & 0.085 \\
\hline Carboxyl & 0.026 & 0.019 & 0.02 & 0.015 & 0.014 & 0.034 \\
\hline Lactone & 2.1 & 1.4 & 11 & 1.4 & 3 & 4.2 \\
\hline Oxidation level & &
\end{tabular}


with singlet oxygen. Differential titration was employed to reveal the generation of the most strong carboxyl groups $\left(p K_{a} \sim 2\right.$-3) using singlet oxygen as the co-agent of the hydrogen peroxide oxidant $[17,25]$.

\section{DISCUSSION}

The decomposition of hydrogen peroxide proceeds via its dissociation as a weak acid [26] by the scheme $\mathrm{H}_{2} \mathrm{O}_{2} \leftrightarrow \mathrm{H}^{+}+\mathrm{OOH}^{-}$ $\left(\not K_{a}=11.6\right)$; so, it is most pronounced in a basic medium. However, the routes of the process are chain reactions yielding active oxygen species (AOS), and in the case of heterogeneous catalysis they were studies only qualitatively [1]. Our study showed that a direct relationship between catalytic activity and specific surface area of carbon black is absent. Surface roughness serves as a disturbing factor. An increase in the roughness may increase the fraction of the end carbon atoms, which are more oxidizable. Indeed, the phenol groups $(\mathrm{C}-\mathrm{OH})$, which are formed upon treatment of carbon black, accelerate the decomposition of hydrogen peroxide, whereas the carboxyl groups $(\mathrm{COOH})$ inhibit the process, as was noted also by other researchers [27].

The catalytic decomposition of hydrogen peroxide over the functional groups of graphene is described by the reactions on the phenol group:

$\mathrm{AC}-\mathrm{OH}+\mathrm{H}_{2} \mathrm{O}_{2} \rightarrow \mathrm{AC}-\mathrm{OOH}+\mathrm{H}_{2} \mathrm{O}$

and on the carboxyl group:

$\mathrm{AC}-\mathrm{OOH}+\mathrm{H}_{2} \mathrm{O}_{2} \rightarrow \mathrm{AC}-\mathrm{OH}+\mathrm{H}_{2} \mathrm{O}+\mathrm{O}_{2}$. [28].

The adsorption of hydrogen peroxide molecules and the donor-acceptor interaction with electron transfer may occur on the basal plane of graphene. This process leads to decomposition of hydrogen peroxide by the radical mechanism similar to the Fenton reaction [29]:

$$
\begin{aligned}
& \mathrm{AC}+\mathrm{H}_{2} \mathrm{O}_{2} \rightarrow \mathrm{AC}^{+}+\mathrm{OH}^{-}+\cdot \mathrm{OH}, \\
& \mathrm{AC}++\mathrm{H}_{2} \mathrm{O}_{2} \rightarrow \mathrm{AC}^{+} \mathrm{H}^{+}+{ }^{\cdot} \mathrm{HO}_{2} .
\end{aligned}
$$

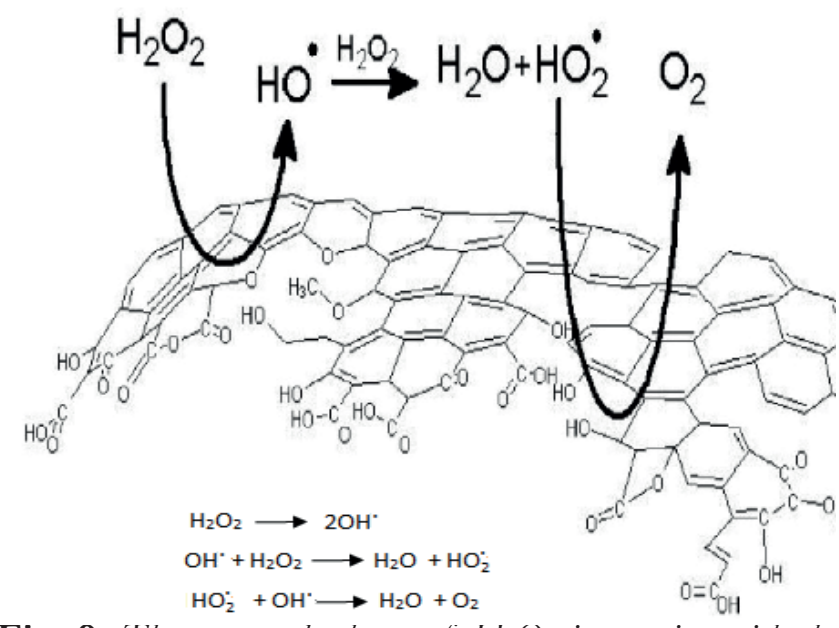

Fig. 9. The proposed scheme of $\mathrm{H}_{2} \mathrm{O}_{2}$ interaction with the carbon surface according to [30].

Different mechanisms of hydrogen peroxide interaction with the graphene layers of carbon black are reflected in the scheme (Fig. 9).

According to this scheme, the hydrogen peroxide molecule is adsorbed on the surface and decomposed on the active sites, which are represented by neutral or weak-acid functional groups. The intermediate products formed on the surface are desorbed and diffuse into the liquid phase; they can form new intermediate products by the reaction with other hydrogen peroxide molecules. The new intermediates diffuse to the carbon surface, interact with it and release molecular oxygen.

Real surface of carbon black contains the oxygen functional groups whose structure changes cyclically during the oxidation of carbon black, as shown in Fig. 10 where cycles of the oxidation process are indicated in parentheses.

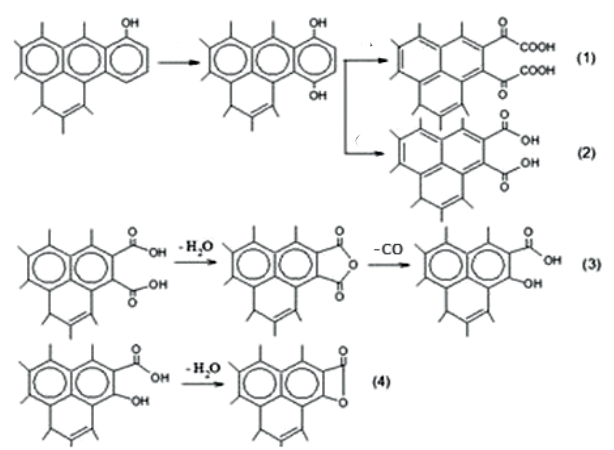

Fig. 10. The proposed scheme of carbon black functionalization. 
A partial destruction of the carbon skeleton makes it difficult to control the oxidation of carbon black. Thus, to predict the structure of its final product, it is necessary to control the structure of the initial material, the conditions of the oxidation process, and the choice of the effective reagent.

\section{CONCLUSION}

The catalytic activities of different carbon black grades were compared in the decomposition of hydrogen peroxide, and the most essential properties of the carbon black surface affecting the kinetic parameter of the reaction, its activation energy, were revealed.

The knowledge of activation energies for the decomposition of hydrogen peroxide by different carbon black grades will make it possible to optimize the selection of the most efficient set of available grades for their joint oxidation and optimization of the functional composition of the product and other process variables.

\section{ACKNOWLEDGMENTS}

The work was performed within the Program of Basic Research of State Academies of Sciences for the period of 2013-2020, direction V.49, Project No. V.49.1.7, using the facilities of the Omsk Shared Equipment Regional Center, Siberian Branch of the Russian Academy of Sciences. The authors are grateful to researchers from the Institute of Hydrocarbons Processing SB RAS: PhD (chem.) M.V. Trenikhin for HRTEM examination of the samples, $\mathrm{PhD}$ (chem.) A.B. Arbuzov for IR and Raman spectroscopy studies, I.V. Muromtsev for X-ray examination of the samples, and PhD (chem.) A.V. Shilova for elemental analysis.

\section{REFERENCES}

1. Schumb WC, Satterfield CN, Wentworth FL. Hydrogen Peroxide. New York, N.Y. Chapman \& Hall LTD, London. Reinold Publishing Corporation, 1955.

2. Posin ME. Hydrogen Peroxide and Peroxidates. Leningrad-Moscow, GKhI Publ., 1951, 242 p.

3. Hydrogen Peroxide //http://www. adentina.com/Perekis_vodoroda

4. Zhubrikov AV, Legurova EA, Gutkin V, Uvarov V, Khitrov NV, Lev O, Tripolskaya TA, Prikhodchenko PV. Issledovanie perkarbonata natriya, granulirovannogo silikatom natriya, metodom rentgenofotoelektronnoy spektroskopii [An X-ray photoelectron spectroscopy study of sodium percarbonate granulated with sodium silicate]. Zhurnal neorganich. khimii, 2009, 54(9):1526-1529 (in Russ.).

5. MischenkoKP andRavdelAA(Eds.).Kratkiy spravochnik fiziko-khimicheskikh velichin [Brief Handbook of Physicochemical Quantities]. Leningrad, Khimiya Publ., 1972, 200 p.

6. Yehia Y., Condit DA, Burlatsky SF, Madden TH. Determination of hydrogen peroxide generation/decomposition kinetics using RRDE on ketjen black, vulcan, 20\% and 50\% Vulcan-supported Pt electrodes. Proc. 206 Meeting of the Electrochemical Society, 3-8 October 2005. Hawaii, 2005, p. 118.

7. Razdyakonova GI, Kokhanovskaya OA. Modifikatsiya tekhnicheskogo ugleroda okisleniem kak sposob polucheniya ego raznovidnostey [Modification of carbon black by oxidation as a method for obtaining its variations]. Kauchuk $i$ Rezina, 2013, 3:2829 (in Russ.).

8. Curtis JC, Joyce GA, Taylor RL. Hydrogen peroxide oxidation of carbon black. Pat. 6120594 US, Fil. 28.04.1999, iss. 19.09.2000.

9. Belyaeva OV, Krasnova TA, Semyonova SA, Gladkova OS. Vzaimodeystvie $\mathrm{O}_{2}, \mathrm{O}_{3} \mathrm{i}$ 
$\mathrm{H}_{2} \mathrm{O}_{2} \mathrm{~s}$ aktivirovannym uglem [Interaction of $\mathrm{O}_{2}, \mathrm{O}_{3}$ and $\mathrm{H}_{2} \mathrm{O}_{2}$ with activated carbon]. Khimiya tverdogo topliva, 2011, 6:61-64 (in Russ.).

10. Razdyakonova GI. Poluchenie $i$ svoystva dispersnogo ugleroda [Synthesis and Properties of Disperse Carbon]. Omsk, OmSTU Publ., 2014, 236 p.

11. Valdes H, Sanchez-Polo M, Rivera-Utrilla J, Zaror CA. Effect of Ozone Treatment on Surface Properties of Activated Carbon. Langmuir, 2002, 18:2111.

12. Novikov AN, Maratkanova EA, Razdyakonova GI, Dikina KV, Novikova AO. Dinamika izmeneniya $\mathrm{pH}$ suspenziy tekhnicheskogo ugleroda pri ego okislenii singletnym kislorodom $\mathrm{v}$ prisutstvii perekisi vodoroda [The $\mathrm{pH}$ dynamics of carbon black suspensions in its oxidation by singlet oxygen in the presence of hydrogen peroxide]. Dynamics of Systems, Mechanisms and Machines, 2014, 3:315-318 (in Russ.).

13. Novikov AN, Maratkanova EA, Razdyakonova GI, Rybakin MS. Izuchenie vozdeystviya aktivnykh form kisloroda na vodnye suspenzii tekhnicheskogo ugleroda [The action of active oxygen species on aqueous suspensions of carbon black]. Dynamics of Systems, Mechanisms and Machines, 2014, 3:312-314 (in Russ.).

14. Razdyakonova GI, Likholobov VA, Moiseevskaya GV, Petin AA, Karavaev $\mathrm{MYu}$. Innovative Disperse Carbon. From Idea to Process. Omsk, OmSTU Publ., 2014, 312 p.

15. Goertzen SL, Theriault KD, Oickle AM, Tarasuk AC, Andreas HA. Standardization of the Boehm titration: Part I. $\mathrm{CO}_{2}$ expulsion and endpoint determination. Carbon, 2010, 48:1252-1261.

16. Oickle AM, Goertzen SL, Hopper KR, Abdalla YO, Andreas HA. Standardization of the Boehm titration: Part II. Method of agitation, effect of filtering and dilute titrant. Carbon, 2010, 48:3313-3322.

17. Razdyakonova GI, Vishnevskaya AYu, Fortuna EG. Priminenie metoda differentsirovannogo potentsiometricheskogo titrovaniya dlya opredeleniya funktsionalnykh grupp na poverkhnosti tekhnicheskogougleroda [The application of differential potentiometric titration for determination of functional groups on the carbon black surface]. Omsk Scientific Bulletin, 2015, 1:244-250 (in Russ.).

18. ASTM D 6556-04 Standard Test Method for Carbon Black/Total and External Surface Area by Nitrogen Adsorption. Annual Book of ASTM Standards, 2005, v. 09.01 November 2006 Rubber, Natural and Synthetic - General Test Methods.

19. Sadezky A, Muckenhuber H, Grothe H, Niessner R., Pöschl U. Raman microspectroscopy of soot and related carbonaceous materials: Spectral analysis and structural information. Carbon, 2005, 43:1731-1742.

20. Avdeenko MA. Heats of chemisorption of simple molecules and some features of the electronic structure of graphite. In: Constructional Materials Based on Graphite. Moscow, Metallurgiya Publ., 1967, 3:63-73. 21. Vershal VV, Medvedeva EN, Rybal'chenko NA, Babkin VA. A study of hydrogen peroxide decomposition in an alkaline medium and its effect on bleaching of lignocellulose and homogeneous oxidation. Chemistry of Plant Feedstock, 1998, 1:45-50.

22. Razdyakonova GI. Ionnoobmennye svoystva poverkhnosti tekhnicheskogo ugleroda [Ion-exchange properties of carbon black surface]. Proc. Intern. (4th National) Symp. on Adsorption and Chromatography of Macromolecules. Moscow, PAIMS, 1994:81-85 (in Russ.). 
23. Kirchstetter TW, Novakov T. Controlled generation of black carbon particles from a diffusion flame and applications in evaluating black carbon measurement methods. Atmospheric Environment, 2007, 41:1874-1888.

24. Ek M, Gierer J, Yansbo K, Reitberger T. Study on selectivity of bleaching with oxygen-containing species. Holiforschung, 1989, 43 (6):391-396.

25. Razdyakonova GI, Kokhanovskaya OA., Likholobov VA. Influence of Environmental Conditions on Carbon Black Oxidation by Reactive Oxygen Intermediates. Procedia Engineering, 2015, 113:43-50.

26. Khalil LB, Girgis BS, Tawfik TA. Decomposition of $\mathrm{H} 2 \mathrm{O} 2$ on activated carbon obtained from olive stones. J. Chem. Technol. and Biotech., 2011, 76:1132-1140.

27. Kurniawan TA, Lo WH. Removal of refractory compounds from stabilized landfill leachate using an integrated $\mathrm{H}_{2} \mathrm{O}_{2}$ oxidation and granular activated carbon (GAC) adsorption treatment. Water. Res., 2009, 43:4079.

28. Bansal RC, Donnet JB, Stoeckli F (Eds.). Active Carbon. Marcel Dekker, New York, 1998.

29. Kimura M, Miyamoto I. Discovery of the activated-carbon radical $(\mathrm{AC}+)$ and the novel oxidation reactions comprising the $\mathrm{AC} / \mathrm{AC}+$ cycles as a catalyst in an aqueous solution, Bull. Chem. Soc. Jpn., 1994, 67:2357.

30. Paternina E, Arias JM, Barragán D. Estudio cinético dela descomposición catalizada deperóxido dehidrógeno sobrecarbón activado, Quim. Nova, 2009, 32(4):934-938. 